06

\title{
Фотоэлектрические поля и особенности вторичной структуры номинально чистых кристаллов ниобата лития, выращенных из шихты, легированной бором
}

\author{
(C) Н.В. Сидоров, Н.А. Теплякова, Р.А. Титов, М.Н. Палатников \\ Институт химии и технологии редких элементов и минерального сырья им. И.В. Тананаева Федерального \\ исследовательского центра „Кольский научный центр РАН“, \\ 184209 Апатиты, Россия \\ e-mail: tepl_na@chemy.kolasc.net.ru
}

Поступило в Редакцию 31 января 2019 г.

В окончательной редакции 25 марта 2019 г.

Принято к публикации 24 октября 2019 г.

\begin{abstract}
Показано, что применение для выращивания номинально чистых кристаллов ниобата лития расплава, структурированного неметаллическим элементом бором, позволяет регулировать особенности вторичной структуры, оптическую однородность, величины фотоэлектрических полей и ширину запрещенной зоны. По характеристикам фотоиндуцированного рассеяния света определены напряженности фотовольтаического и диффузионного полей в номинально чистых кристаллах $\mathrm{LiNbO}_{3}$ : В. Показано, что величина диффузионного поля, определяющая концентрацию мелких электронных ловушек, для кристаллов $\mathrm{LiNbO}_{3}: \mathrm{B}$ имеет промежуточное значение между кристаллами конгруэнтного и стехиометрического составов и зависит от концентрации бора в шихте. При этом ширина запрещенной зоны в кристаллах $\mathrm{LiNbO}_{3}$ : В соответствует значению для стехиометрического кристалла, но оптическая однородность кристаллов $\mathrm{LiNbO}_{3}$ : В близка к оптической однородности конгруэнтного кристалла, концентрация ОН-групп в кристаллах $\mathrm{LiNbO}_{3}: \mathrm{B}$ меньше, а их расположение в структуре более упорядочено, чем в конгруэнтном кристалле.
\end{abstract}

Ключевые слова: ниобат лития, расплав, фотоэлектрические поля, ИК-спектроскопия, оптическая спектроскопия.

DOI: $10.21883 / J T F .2020 .04 .49091 .30-19$

\section{Введение}

Ранее нами методами спектроскопии комбинационного рассеяния света (КРС), фотоиндуцированного рассеяния света (ФИРС) и лазерной коноскопии были исследованы кристаллы $\mathrm{LiNbO}_{3}$, выращенные из шихты, легированной бором [1-7]. Неметаллический элемент бор не входит в структуру кристалла $\mathrm{LiNbO}_{3}$. Несмотря на высокое содержание бора в шихте (до $2.0 \mathrm{~mol} \%$ ), его концентрация в кристалле находится на уровне следовых количеств $\left(\sim 10^{-4}-10^{-5}\right.$ wt.\%), т.е. на порядки ниже концентрации легирующих металлических добавок $(\mathrm{Mg}$, $\mathrm{Zn}, \mathrm{Gd}, \mathrm{Sc}, . .$.$) , обычно используемых для повышения$ оптической стойкости кристалла ниобата лития. Было показано, что путем направленного структурирования конгруэнтного расплава $(\mathrm{Li} / \mathrm{Nb}=0.946)$ бором можно получать номинально чистые кристаллы $\mathrm{LiNbO}_{3}$, обладающие такими же свойствами, как и легированные большими концентрациями „нефоторефрактивных“ примесей $(\mathrm{Mg}, \mathrm{Zn}, \mathrm{Gd}, \mathrm{Sc}, \ldots)$ конгруэнтные кристаллы, но по упорядочению структурных единиц катионной подрешетки и количеству дефектов $\mathrm{Nb}_{\mathrm{Li}}$ приближающиеся к кристаллу стехиометрического состава $(\mathrm{Li} / \mathrm{Nb}=1)$. Стехиометрические кристаллы отличаются более чем в 5 раз низким коэрцитивным полем по сравнению с конгруэнтными кристаллами и обладают определенными преимуществами для создания преобразователей опти- ческого излучения на периодически поляризованных доменах субмикронных размеров [8]. В то же время монокристаллы $\mathrm{LiNbO}_{3}$ : В обладают существенно меньшим эффектом фоторефракции, чем стехиометрические кристаллы [5-7,9].

Для объяснения влияния бора на структуру расплава были рассмотрены химические взаимодействия в системе $\mathrm{Li}_{2} \mathrm{O}-\mathrm{B}_{2} \mathrm{O}_{3}-\mathrm{Nb}_{2} \mathrm{O}_{5}$ [5,7]. Было показано, что оксидные соединения бора, как сильные комплексообразователи и растворители, образуя устойчивые в расплаве ковалентные связи с ниобийсодержащими полианионами, связывают избыток катионов ниобия и увеличивают тем самым отношение $\mathrm{Li} / \mathrm{Nb}$ в расплаве. Кроме того, соединения бора, очевидно, снижают содержание неконтролируемых металлических примесей в расплаве. В результате выращенный кристалл приближается к стехиометрическому кристаллу по степени упорядочения структурных единиц катионной подрешетки, содержанию дефектов $\mathrm{Nb}_{\mathrm{Li}}$ и литиевых вакансий $V_{\mathrm{Li}}$. При этом увеличивается степень „возмущения“ кислородных октаэдров $\mathrm{O}_{6}$ и снижается фоторефрактивный отклик выращенных кристаллов $\mathrm{LiNbO}_{3}$ : В по сравнению со стехиометрическим кристаллом [2,5,7].

В настоящей работе приведены результаты исследований спектров оптического поглощения и инфракрасных (ИК) спектров поглощения в области валентных колебаний ОН-групп кристаллов $\mathrm{LiNbO}_{3}$ : В (0.55-0.83 mol.\% 
$\mathrm{B}_{2} \mathrm{O}_{3}$ в шихте). Для сравнения исследованы номинально чистые стехиометрический $\left(\mathrm{LiNbO}_{3 \text { stoich }}\right)$ и конгруэнтный $\left(\mathrm{LiNbO}_{3 \text { cong }}\right)$ кристаллы ниобата лития. Положения атомов водорода в структуре кристалла $\mathrm{LiNbO}_{3}$ чрезвычайно чувствительны к изменению кристаллического поля, а особенности края фундаментального поглощения - к структурной однородности кристалла $[4-7,10,11]$. Исследование положения края фундаментального поглощения, а также метод ИК-спектроскопии в области валентных колебаний ОН-групп позволяют оценить отношение $\mathrm{Li} / \mathrm{Nb}$, концентрацию в кристалле точечных дефектов $\mathrm{Nb}_{\mathrm{Li}}$ и $V_{\mathrm{Li}}$ и характер образуемых ими комплексных дефектов с ОН-группами. По характеристикам индикатрисы спекл-структуры ФИРС, используя подход, предложенный в работе [12], оценены фотоэлектрические поля (фотовольтаическое $E_{p v}$ и диффузионное $\left.E_{D}\right)$ в исследуемых кристаллах.

\section{1. Методика эксперимента}

Кристаллы выращивались методом Чохральского в воздушной атмосфере на установке „Кристалл-2“, снабженной системой автоматического контроля диаметра кристалла. Номинально чистые конгруэнтный и стехиометрический кристаллы $\mathrm{LiNbO}_{3}$ выращивались из расплавов конгруэнтного состава и расплава с содержанием $\mathrm{Li}_{2} \mathrm{O}$, равным $58.6 \mathrm{~mol} \%$ со сответственно. Использовалась оригинальная гранулированная шихта ниобата лития с высокой насыпной плотностью, синтезированная в ИХТРЭМС КНЦ РАН [13]. Содержание следовых количеств примесей в кристалле не превышало 0.5-1.0 $\cdot 10^{-4}$ wt.\%. Легирование кристаллов $\mathrm{LiNbO}_{3}$ : В осуществлялось методом прямого твердофазного легирования [14], суть которого заключается в твердофазном синтезе смеси пентаоксида ниобия, карбоната лития и борной кислоты с последующим получением гранулированной шихты в процессе прокаливания смеси в температурной области предплавления $\left(1240-1250^{\circ} \mathrm{C}\right)$. Содержание бора в выращенных кристаллах находилось на уровне следовых количеств $\sim 10^{-4}-10^{-5} \mathrm{wt} . \%$.

Образцы для исследований имели форму параллелепипедов с ребрами, параллельными кристаллофизическим осям $X, Y, Z$ соответственно. Ось $Z$ совпадает по направлению с полярной осью кристалла $P_{s}$. Грани параллелепипедов тщательно полировались.

Регистрация ФИРС осуществлялась с помощью установки, подробно описанной в работах $[15,16]$. Для возбуждения ФИРС использовались линии генерации аргонового лазера фирмы Spectra Physics (модель 2018-RM): $476.5(P=216 \mathrm{~mW}) ; 488.0(P=98 \mathrm{~mW})$; $514.5(P=282 \mathrm{~mW}) ; 532.0 \mathrm{~nm}(P=160 \mathrm{~mW})$. Диаметр лазерного пучка составлял $1.8 \mathrm{~mm}$. Регистрация ФИРС осуществлялась в геометрии $е e$-типа, т.е. падающее на кристалл и рассеянное лазерное излучение имеют одну и ту же поляризацию, при этом вектор $\mathbf{E}$ ориентирован параллельно полярной оси кристалла (ось $Z$ ).
По параметрам индикатрисы ФИРС в исследованных кристаллах были определены значения напряженностей фотовольтаического и диффузионного электрических полей. Погрешность вычислений фотоэлектрических полей в условиях эксперимента составляет 1.5-2\%. Расчет величины напряженности фотовольтаического и диффузионного полей в кристаллах осуществлялся в программе Mathcad 15.0 с использованием подхода, предложенного в работе [12]. Показатели преломления необыкновенного и обыкновенного лучей определялись из эмпирических уравнений, приведенных в справочнике [17].

Определение края поглощения производилось с помощью спектрофотометра Cary 2300. Для определения ширины запрещенной зоны регистрировался спектр поглощения кристалла. Полученный спектр поглощения в убывающей линейной части графика аппроксимировался прямой до пересечения с осью абсцисс. Точка пересечения этой прямой и оси абсцисс является длиной волны, соответствующей краю поглощения кристалла. Ширина запрещенной зоны определялась по формуле $E=h c / \lambda$, где $\lambda-$ длина волны, соответствующая краю поглощения, $h-$ постоянная Планка, $c-$ скорость света в вакууме. Точность определения границы края поглощения составляет $\pm 1.0 \mathrm{~nm}$.

Регистрация ИК-спектров производилась с помощью спектрометра IFS 66 v/s фирмы Bruker.

\section{2. Результаты и их обсуждение}

На рис. 1 приведены спектры оптического поглощения кристаллов $\mathrm{LiNbO}_{3 \text { cong, }}, \mathrm{LiNbO}_{3 \text { stoich }}$ и $\mathrm{LiNbO}_{3}: \mathrm{B}$ (0.55, $0.83 \mathrm{~mol} \% \mathrm{~B}_{2} \mathrm{O}_{3}$ в шихте). Видно, что край поглощения кристаллов $\mathrm{LiNbO}_{3}$ : В смещен в длинноволновую область по сравнению с краем поглощения кристаллов конгруэнтного и стехиометрического составов, однако при этом спектр поглощения кристаллов $\mathrm{LiNbO}_{3}: \mathrm{B}$ имеет более крутой подъем по сравнению со спектром кристалла $\mathrm{LiNbO}_{3 \text { stoich, }}$ что указывает на большую

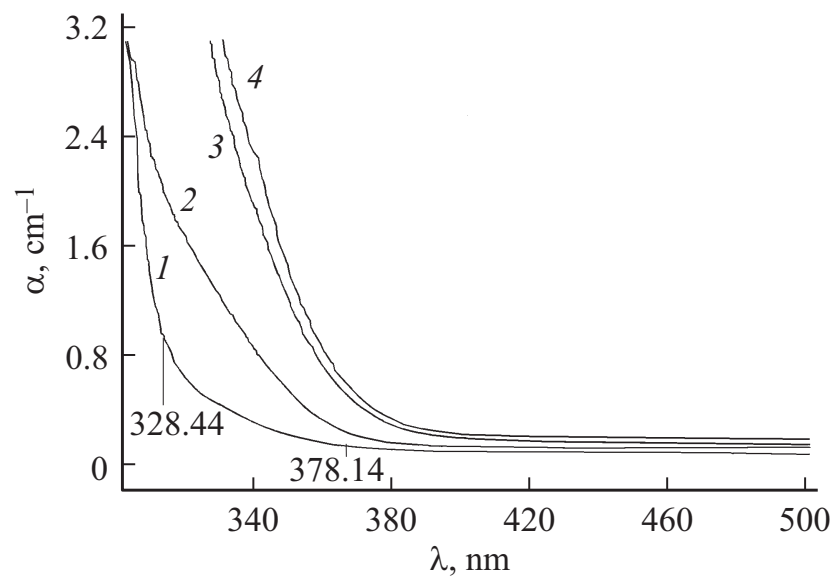

Рис. 1. Спектры поглощения кристаллов $\mathrm{LiNbO}_{3 \text { cong }}(1)$, $\mathrm{LiNbO}_{3 \text { stoich }}$ (2), $\mathrm{LiNbO}_{3}: \mathrm{B}\left(0.55\right.$ mol.\% $\mathrm{B}_{2} \mathrm{O}_{3}$ в шихте) (3), $\mathrm{LiNbO}_{3}$ : B (0.83 mol.\% B $\mathrm{O}_{3}$ в шихте) (4). 
оптическую однородность кристаллов, выращенных из шихты, легированной бором. Считается, что основной вклад в изменение положения края фундаментального поглощения в номинально чистых конгруэнтных кристаллах ниобата лития вносят дефекты $\mathrm{Nb}_{\mathrm{Li}}[18,19]$. По положению края фундаментального поглощения можно оценить концентрацию имеющихся собственных дефектов $\left(\mathrm{Nb}_{\mathrm{Li}}\right.$ и $\left.V_{\mathrm{Li}}\right)$, а также отношение $\mathrm{Li} / \mathrm{Nb}$ (характеризующее отклонение от стехиометрии) и делать выводы о механизме вхождения нефоторефрактивных примесей в кристаллическую решетку.

В [19] обнаружено совпадение концентрационных зависимостей дефектов $\mathrm{Nb}_{\mathrm{Li}}$ и параметра Урбаха от отношения $\mathrm{Li} / \mathrm{Nb}$ в кристалле, что согласуется с выводами работы [20] о том, что поглощение Урбаха происходит в кристалле ниобата лития в результате перехода электронов из заполненных состояний „2 $2 p^{“}$ кислорода на пустые состояния „ $4 d “$ ниобия. Уменьшение концентрации дефектов $\mathrm{Nb}_{\mathrm{Li}}$ при приближении отношения $\mathrm{Li} / \mathrm{Nb}$ к единице приводит к смещению края фундаментального поглощения в длинноволновую сторону в результате уменьшения плотности связанных с дефектами $\mathrm{Nb}_{\mathrm{Li}}$ локальных состояний вблизи дна зоны проводимости. Под действием света в кристалле ниобата лития возможен переход из валентной зоны на эти состояния. Из рис. 1 видно, что край поглощения максимально сдвинут в коротковолновую область для кристалла $\mathrm{LiNbO}_{3 \text { cong. }}$. По формулам, предложенным в [19], мы рассчитали отношение $\mathrm{Li} / \mathrm{Nb}$, а также концентрацию собственных дефектов в кристалле $\mathrm{LiNbO}_{3 \text { cong }}: \mathrm{Li} / \mathrm{Nb}=0.89$, $C\left(V_{\mathrm{Li}}\right)=7.47 \mathrm{~mol} . \%$ и $C\left(\mathrm{Nb}_{\mathrm{Li}}\right)=1.87 \mathrm{~mol} . \%$, что не совпадает с результатами, полученными авторами работы [19]. Известно, что кристаллы конгруэнтного состава характеризуются дефицитом по Li около $6 \mathrm{~mol}$. $(\mathrm{Li} / \mathrm{Nb}=0.946)$ [18]. Согласно модели компенсации $\mathrm{Li}$-вакансий, в кристаллической решетке конгруэнтного кристалла $\mathrm{LiNbO}_{3}$ существует $\sim 1 \mathrm{~mol} \%$ точечных дефектов $\mathrm{Nb}_{\mathrm{Li}}^{4+}$ и $\sim 4$ mol.\% точечных дефектов $V_{\mathrm{Li}}[21,22]$. В идеальном стехиометрическом кристалле дефектов $\mathrm{Nb}_{\mathrm{Li}}$ нет вообще.

Кристаллы $\mathrm{LiNbO}_{3}$ : В (0.55 и 0.83 mol.\% $\quad \mathrm{B}_{2} \mathrm{O}_{3} \quad$ в шихте), исследованные в настоящей работе, по степени упорядочения структурных единиц катионной подрешетки, по содержанию точечных дефектов $\mathrm{Nb}_{\mathrm{Li}}$ и $V_{\mathrm{Li}}$ занимают промежуточное положение между конгруэнтным и стехиометрическим кристаллами [5]. Приближение к стехиометрии в кристаллах $\mathrm{LiNbO}_{3}$ : В возможно путем связывания избыточного ниобия в конгруэнтном расплаве за счет комплексообразующей способности соединений бора [5]. Очевидно, что положение края фундаментального поглощения определяется не только концентрацией дефектов $\mathrm{Nb}_{\mathrm{Li}}$ и $V_{\mathrm{Li}}$. Кроме глубоких ловушек электронов, создаваемых точечными фоторефрактивными центрами (главным образом, дефектами $\mathrm{Nb}_{\mathrm{Li}}$ ), в кристалле $\mathrm{LiNbO}_{3}$ существует множество мелких ловушек электронов, влияющих на эффект фоторефракции [18,23-25]. Причем количество мелких элек-
Таблица 1. Фотоэлектрические параметры ФИРС и ширина запрещенной зоны кристаллов ниобата лития при $t=25^{\circ} \mathrm{C}$

\begin{tabular}{l|c|c|c|c|c}
\hline \multirow{2}{*}{ Кристалл } & \multirow{2}{*}{$\begin{array}{c}\theta, \\
{ }^{\circ} \mathrm{C}\end{array}$} & $\begin{array}{c}\lambda_{k}, \\
\mathrm{~nm}\end{array}$ & $\begin{array}{c}\Delta E_{g}, \\
\mathrm{eV}\end{array}$ & \multicolumn{2}{|c}{$\lambda=532.0 \mathrm{~nm}$} \\
\cline { 5 - 6 } & & & & $E_{p v}, \mathrm{~V} / \mathrm{cm}$ & $E_{D}, \mathrm{~V} / \mathrm{cm}$ \\
\hline $\mathrm{LiNbO}_{3 \text { stoich }}$ & 56 & 367 & 3.38 & 4055 & 1749 \\
${ }^{*} \mathrm{LiNbO}_{3 \text { cong }}$ & & 328 & 3.78 & 5003 & 52 \\
$\mathrm{LiNbO}_{3}: \mathrm{B}(0.55 \mathrm{~mol} \%$ & 14 & 367 & 3.38 & 5458 & 572 \\
$\left.\mathrm{~B}_{2} \mathrm{O}_{3}\right)$ в шихте $)$ & & & & & \\
$\mathrm{LiNbO}_{3}: \mathrm{B}(0.83$ mol.\% & 22 & 368 & 3.37 & 5554 & 25 \\
$\mathrm{~B}_{2} \mathrm{O}_{3}$ в шихте) & & & & &
\end{tabular}

Прим ечан и е. * Для кристалла $\mathrm{LiNbO}_{3 \text { cong }}$ индикатриса ФИРС не развивается при $I \sim 6.29 \mathrm{~W} / \mathrm{cm}^{2}$.

тронных ловушек существенно зависит от отношения $\mathrm{Li} / \mathrm{Nb}[18]$. При воздействии лазерного излучения на кристалл $\mathrm{LiNbO}_{3}$ в результате процессов фотовозбуждения (дрейф и диффузия электронов) происходит пространственное разделение заряда и возникает внутреннее электрическое поле, приводящее к фотоиндуцированному изменению показателей преломления [23-26]. При этом должно происходить изменение ширины запрещенной зоны, которая для номинально чистого конгруэнтного кристалла составляет $3.72 \mathrm{eV}$, что близко к значению, характерному для широкозонных полупроводников [25].

В табл. 1 приведены результаты расчета ширины запрещенной зоны по спектрам поглощения кристаллов $\mathrm{LiNbO}_{3}$ разного состава, значения угла раскрытия спеклструктуры индикатрисы ФИРС и фотоэлектрических полей (фотовольтаического $E_{p v}$ и диффузионного $E_{D}$ ), рассчитанные по формулам [12]:

$$
\begin{gathered}
E_{p v}=\frac{\lambda\left(\Gamma_{-c}+\Gamma_{+c}\right)}{2 \pi\left[\begin{array}{c}
n_{e}^{3} r_{33} \sqrt{\cos \theta_{S}^{i n}} \cos \left(\frac{\theta_{S}^{\epsilon}}{2}\right)+n_{e} n_{o}^{2} r_{51} \times \\
\times \sqrt{\tan \theta_{S}^{i n} \sin \theta_{S}^{i n}} \sin \left(\frac{\theta_{S}^{i n}}{2}\right)
\end{array}\right]}, \\
E_{D}=\frac{\lambda\left(\Gamma_{-c}-\Gamma_{+c}\right)}{2 \pi\left[\begin{array}{c}
n_{e}^{3} r_{33} \sqrt{\cos \theta_{S}^{i n}} \cos \left(\frac{\theta_{S}^{\epsilon}}{2}\right)+n_{e} n_{o}^{2} r_{51} \times \\
\times \sqrt{\tan \theta_{S}^{i n} \sin \theta_{S}^{i n}} \sin \left(\frac{\theta_{S}^{i n}}{2}\right)
\end{array}\right]},
\end{gathered}
$$

где $E_{p v}$ - фотовольтаическое поле, $E_{D}$ - диффузионное поле, $\lambda$ - длина волны, $\theta_{S}^{\text {in }}-$ угол рассеянного излучения, $\Gamma_{-c}$ и $\Gamma_{+c}$ - коэффициенты усиления (индексы „--“ и „+“ указывают направление рассеянного излучения против и вдоль направления полярной оси кристалла соответственно), $n_{e}$ и $n_{0}$ - показатели преломления необыкновенного и обыкновенного луча соответственно, $r_{33}$ и $r_{51}$ - электрооптические коэффициенты для $\mathrm{LiNbO}_{3}$. 
Коэффициент усиления $\Gamma\left(\theta_{S}^{\text {in }}\right)$ зависимости от угла ФИРС можно вычислить по формуле [12]:

$$
\Gamma\left(\theta_{S}^{i n}\right)=\frac{1}{l_{\mathrm{eff}}}\left(\theta_{S}^{i n}\right) \ln \frac{I_{S}\left(\theta_{S}^{i n}\right)}{I_{S O}^{\Omega}\left(\theta_{S}^{i n}\right)},
$$

где $I_{s}-$ интенсивность рассеянного излучения, $I_{S O}^{\Omega}-$ интенсивность первичного рассеяния (падающего луча), $l_{\text {eff }}-$ эффективный интервал взаимодействия, который вычисляется в зависимости от угла рассеяния, согласно следующим формулам [12]:

$$
\begin{aligned}
& l_{\mathrm{eff}}=\frac{d}{\cos \theta_{S}^{i n}} \text { при } \theta_{S}^{i n}<\arctan \left(\frac{w_{p}}{2 d}\right), \\
& l_{\mathrm{eff}}=\frac{d}{\sin \theta_{S}^{i n}} \text { при } \theta_{S}^{i n}>\arctan \left(\frac{w_{p}}{2 d}\right),
\end{aligned}
$$

где $d-$ толщина кристалла, $w_{p}-$ диаметр лазерного луча.

На рис. 2, 3 показано угловое распределение интенсивности рассеянного излучения при разных длинах волн и зависимости $E_{D}(a)$ и $E_{p v}(b)$ от длины волны для исследованных кристаллов $\mathrm{LiNbO}_{3}$.

Видно, что ширина запрещенной зоны для исследованных кристаллов находится в диапазоне $3.37-3.78 \mathrm{eV}$ (табл. 1). Наименьшую ширину запрещенной зоны имеют кристаллы $\mathrm{LiNbO}_{3}$ : В и $\mathrm{LiNbO}_{3 \text { stoich }}$ (табл. 1), а наибольшую - кристалл $\mathrm{LiNbO}_{3 \mathrm{cong}}=3.78 \mathrm{eV}$ (согласно [27], ширина запрещенной зоны для номинально чистого конгруэнтного кристалла составляет $3.72 \mathrm{eV}$ ). Преимущественным механизмом фоторефракции в кристалле $\mathrm{LiNbO}_{3}$ является фотовольтаический механизм, т.е. значение величины фотовольтаического поля $\left(E_{p v}\right)$ значительно больше значения величины диффузионного поля $\left(E_{D}\right)[25]$. Из табл. 1 и рис. 2,3 видно, что чем большие фотоэлектрические поля создаются в кристалле, тем больше угол рассеяния $\theta$ и тем асимметричнее индикатриса ФИРС. При этом наименьшим значением фотовольтаического поля $E_{p v}$, которое определяет величину наведенного двулучепреломления (эффекта фоторефракции), при длинах волн возбуждающего излучения 476.5, $488.0,514.5$ и $532.0 \mathrm{~nm}$ обладает кристалл $\mathrm{LiNbO}_{3 \text { stoich }}$. Полученные данные свидетельствуют и о том, что в кристалле $\mathrm{LiNbO}_{3 \text { stoich }}$ сильнее, чем в других кристаллах, проявляется диффузионный механизм переноса заряда, что характерно для кристаллов с большим количеством мелких ловушек электронов.

Обращает на себя внимание, что для кристалла $\mathrm{LiNbO}_{3}: \mathrm{B}\left(0.55 \mathrm{~mol} . \% \mathrm{~B}_{2} \mathrm{O}_{3}\right.$ в шихте $)$ в отличие от остальных кристаллов отсутствует максимум в зависимости $E_{D}$ при длине возбуждающей лазерной линии $514.5 \mathrm{~nm}$ (рис. 3). Для всех остальных кристаллов при длине возбуждающей лазерной линии $514.5 \mathrm{~nm}$ наблюдается максимум в зависимости $E_{p v}$ (рис. 3). В случае кристаллов $\mathrm{LiNbO}_{3}$, выращенных из шихты с содержанием бора 0.55 и $0.83 \mathrm{~mol} . \%$, значения $E_{p v}$ близки 5458 и $5554 \mathrm{~V} / \mathrm{cm}$ соответственно. Бросается в глаза и то, что значение диффузионного поля $E_{D}$ для кристалла $\mathrm{LiNbO}_{3}: \mathrm{B}\left(0.83 \mathrm{~mol} . \% \mathrm{~B}_{2} \mathrm{O}_{3}\right.$ в шихте) близко к значению $E_{D}$ для конгруэнтного кристалла, что может указывать на практически равное количество мелких ловушек электронов в этих кристаллах. Для кристалла $\mathrm{LiNbO}_{3}$ : В $\left(0.55 \mathrm{~mol} . \% \mathrm{~B}_{2} \mathrm{O}_{3}\right.$ в шихте) значение диффузионного поля $E_{D}$ значительно больше, чем для кристаллов $\mathrm{LiNbO}_{3 \text { cong }}$ и $\mathrm{LiNbO}_{3}$ : В $\left(0.83 \mathrm{~mol} \% \mathrm{~B}_{2} \mathrm{O}_{3}\right.$ в шихте), при этом угол раскрытия индикатрисы ФИРС минимален (табл. 1).

Заметное влияние на распределение зарядов в кристалле оказывают особенности локализации протонов, которые всегда присутствуют в структуре кристаллов $\mathrm{LiNbO}_{3}$, выращенных в воздушной атмосфере $[10,11]$. Причем протоны чрезвычайно чувствительны к изменению кристаллического поля. Присутствие $\mathrm{OH}^{-}$групп в структуре кристалла $\mathrm{LiNbO}_{3}$ повышает проводимость и эффект фоторефракции, а также понижает величину коэрцитивного поля $[10,28]$. Валентные и деформационные колебания $\mathrm{OH}^{-}$групп хорошо проявляются в ИК-спектре поглощения кристалла $\mathrm{LiNbO}_{3}$ в области $3450-3550 \mathrm{~cm}^{-1}$. Причем, количество линий, соответствующих колебаниям ОН-групп, их основные параметры (частота, ширина, интенсивность) зависят от стехиометрии, особенностей легирования и выращивания монокристалла [11], т.е. от состава кристалла $\mathrm{LiNbO}_{3}$ и условий его получения. В спектре ИК-поглощения стехиометрического кристалла $\mathrm{LiNbO}_{3}$ высокой степени структурного совершенства, в котором практически отсутствуют точечные дефекты $\mathrm{Nb}_{\mathrm{Li}}$ и связанные с ними комплексные дефекты, обусловленные наличием водородных связей, в области валентных колебаний ОН-групп наблюдается одна узкая полоса поглощения $\left(S=3 \mathrm{~cm}^{-1}\right.$ при $\left.300 \mathrm{~K}\right)$ с частотой $3466 \mathrm{~cm}^{-1}[10,29]$. При отклонении от стехиометрии, в частности, в спектре конгруэнтного кристалла, наблюдаются три широких компонента одинаковой поляризации: полосы поглощения с частотами 3466,3481 и $3489 \mathrm{~cm}^{-1}$ [30]. Исследуя концентрационные зависимости параметров линий и полос в ИК-спектре, соответствующих валентным колебаниям ОН-групп, можно получить важную информацию о характере точечных $\left(\mathrm{Nb}_{\mathrm{Li}}\right.$ и $\left.V_{\mathrm{Li}}\right)$ дефектов и многочисленных комплексных дефектов, обусловленных наличием водородных связей, и их локализации в структуре.

На рис. 4 приведены спектры ИК-поглощения в области валентных колебаний ОН-групп кристаллов: $\mathrm{LiNbO}_{3 \text { stoich }}, \mathrm{LiNbO}_{3 \text { cong }}$ и $\mathrm{LiNbO}_{3}$ : В $(0.55-0.83 \mathrm{~mol} \%$ $\mathrm{B}_{2} \mathrm{O}_{3}$ в шихте). В табл. 2 приведены значения частот, ширин и интенсивностей наблюдаемых линий. Из рис. 4 и табл. 2 видно, что в области валентных колебаний $\mathrm{OH}^{-}$групп для кристаллов $\mathrm{LiNbO}_{3 \text { cong }}$ и $\mathrm{LiNbO}_{3}$ : В наблюдается расщепление полосы поглощения ОН-групп на три компонента одинаковой поляризации с частотами $\sim 3470, \sim 3483$ и $\sim 3486 \mathrm{~cm}^{-1}$, что свидетельствует об одинаковом характере водородных связей в структуре этих кристаллов. В литературе три 

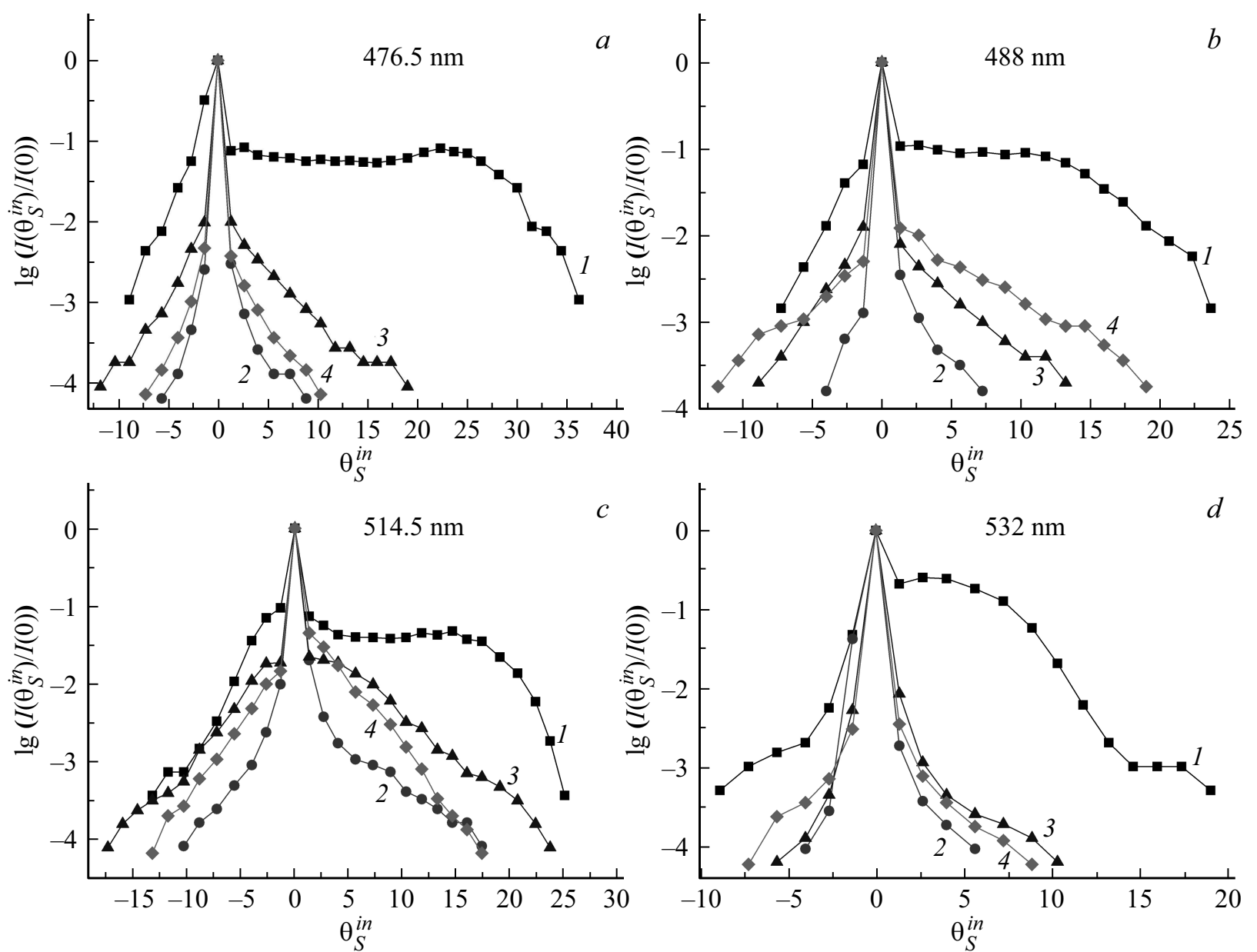

Рис. 2. Угловое распределение интенсивности рассеянного излучения при $\lambda=476.5(a), 488.0(b), 514.5(c), 532.0 \mathrm{~nm}(d)$ для кристаллов: $\mathrm{LiNbO}_{3 \text { stoich }}-1, \mathrm{LiNbO}_{3 \text { cong }}-2, \mathrm{LiNbO}_{3}: \mathrm{B}\left(0.55\right.$ mol.\% $\left.\mathrm{B}_{2} \mathrm{O}_{3}\right)-3, \mathrm{LiNbO}_{3}: \mathrm{B}\left(0.83\right.$ mol.\% $\mathrm{B}_{2} \mathrm{O}_{3}$ в шихте $)-4$.
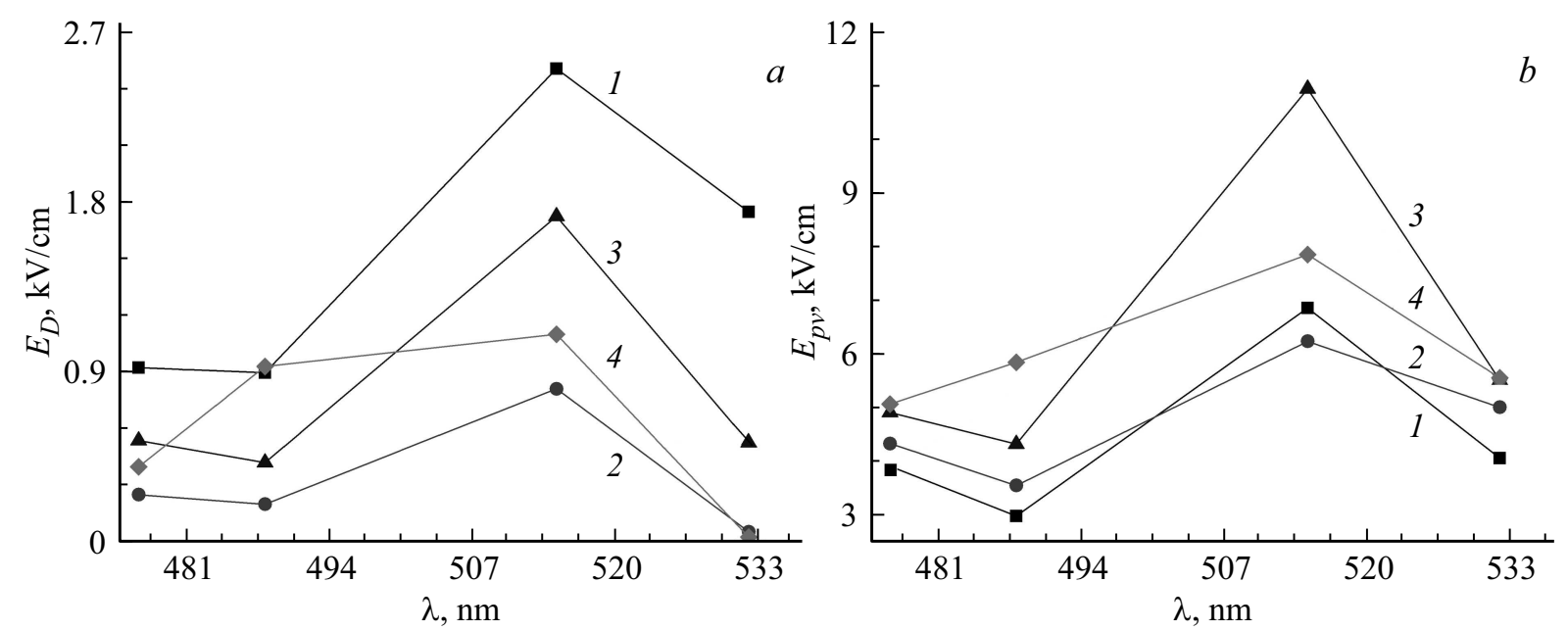

Рис. 3. Зависимость $E_{D}(a)$ и $E_{p v}(b)$ от длины волны для кристаллов $\mathrm{LiNbO}_{3}$ разного состава: $\mathrm{LiNbO}_{3 \text { stoich }}-1, \mathrm{LiNbO}_{3 \text { cong }}-2$, $\mathrm{LiNbO}_{3}$ : В $\left(0.55\right.$ mol.\% $\left.\mathrm{B}_{2} \mathrm{O}_{3}\right)-3, \mathrm{LiNbO}_{3}: \mathrm{B}\left(0.83\right.$ mol.\% $\mathrm{B}_{2} \mathrm{O}_{3}$ в шихте $)-4$.

компонента полосы поглощения в ИК-спектре конгруэнтных кристаллов $\mathrm{LiNbO}_{3}$ связывают с валентными колебаниями ОН-групп, находящихся вблизи дефектов
$\mathrm{Nb}_{\mathrm{Li}}^{4+}-V_{\mathrm{Li}}^{-}$[30,31]. Однако в ИК-спектре кристаллов $\mathrm{LiNbO}_{3}: \mathrm{B}$ интенсивности всех компонентов полосы поглощения выше, чем в спектре конгруэнтного кри- 
Таблица 2. Значения частот $\left(v, \mathrm{~cm}^{-1}\right)$, ширин $\left(S, \mathrm{~cm}^{-1}\right)$ и интенсивностей (I, а.u.) линий в ИК-спектрах поглощения и концентрации ОН-групп $\left(C\left(\mathrm{OH}^{-}\right) / \mathrm{cm}^{-3}\right)$ в кристаллах $\mathrm{LiNbO}_{3 \text { stoich, }} \mathrm{LiNbO}_{3 \text { cong }}, \mathrm{LiNbO}_{3}: \mathrm{B}\left(0.55-0.83\right.$ mol\% $\mathrm{B}_{2} \mathrm{O}_{3}$ в шихте $)$ при $t=25^{\circ} \mathrm{C}$

\begin{tabular}{|c|c|c|c|c|c|c|c|c|c|c|c|c|c|c|}
\hline \multicolumn{3}{|c|}{$\mathrm{LiNbO}_{3 \text { stoich }}$} & \multicolumn{3}{|c|}{$\mathrm{LiNbO}_{3 \text { cong }}$} & \multicolumn{3}{|c|}{$\begin{array}{c}\mathrm{LiNbO}_{3}: \mathrm{B} \\
\left(0.55 \text { mol.\% } \mathrm{B}_{2} \mathrm{O}_{3}\right. \\
\text { в шихте })\end{array}$} & \multicolumn{3}{|c|}{$\begin{array}{c}\mathrm{LiNbO}_{3}: \mathrm{B} \\
\left(0.69 \text { mol.\% } \mathrm{B}_{2} \mathrm{O}_{3}\right. \\
\text { в шихте })\end{array}$} & \multicolumn{3}{|c|}{$\begin{array}{c}\mathrm{LiNbO}_{3}: \mathrm{B} \\
\left(0.83 \text { mol.\% } \mathrm{B}_{2} \mathrm{O}_{3}\right. \\
\text { в шихте })\end{array}$} \\
\hline$v$ & $I$ & $S$ & $v$ & $I$ & $S$ & $v$ & $I$ & $S$ & $v$ & $I$ & $S$ & $v$ & $I$ & $S$ \\
\hline 3465 & 0.14 & 4.28 & 3470 & 0.12 & 16.4 & 3466 & 0.144 & 12.5 & 3466 & 0.100 & 16.2 & 3467 & 0.142 & 12.5 \\
\hline 3480 & 0.11 & 5.37 & 3483 & 0.49 & 24.8 & 3480 & 0.077 & 17.7 & 3481 & 0.130 & 20.1 & 3480 & 0.119 & 19.9 \\
\hline 3488 & 0.07 & 8.18 & 3486 & 0.33 & 27.1 & 3485 & 0.333 & 27.7 & 3485 & 0.104 & 22.6 & 3485 & 0.288 & 27.2 \\
\hline \multicolumn{15}{|c|}{$C\left(\mathrm{OH}^{-}\right) / \mathrm{cm}^{-3}$} \\
\hline \multicolumn{3}{|c|}{$1.6 \cdot 10^{17}$} & \multicolumn{3}{|c|}{$3.3 \cdot 10^{17}$} & \multicolumn{3}{|c|}{$6.4 \cdot 10^{17}$} & \multicolumn{3}{|c|}{$3.4 \cdot 10^{17}$} & \multicolumn{3}{|c|}{$6.3 \cdot 10^{17}$} \\
\hline
\end{tabular}

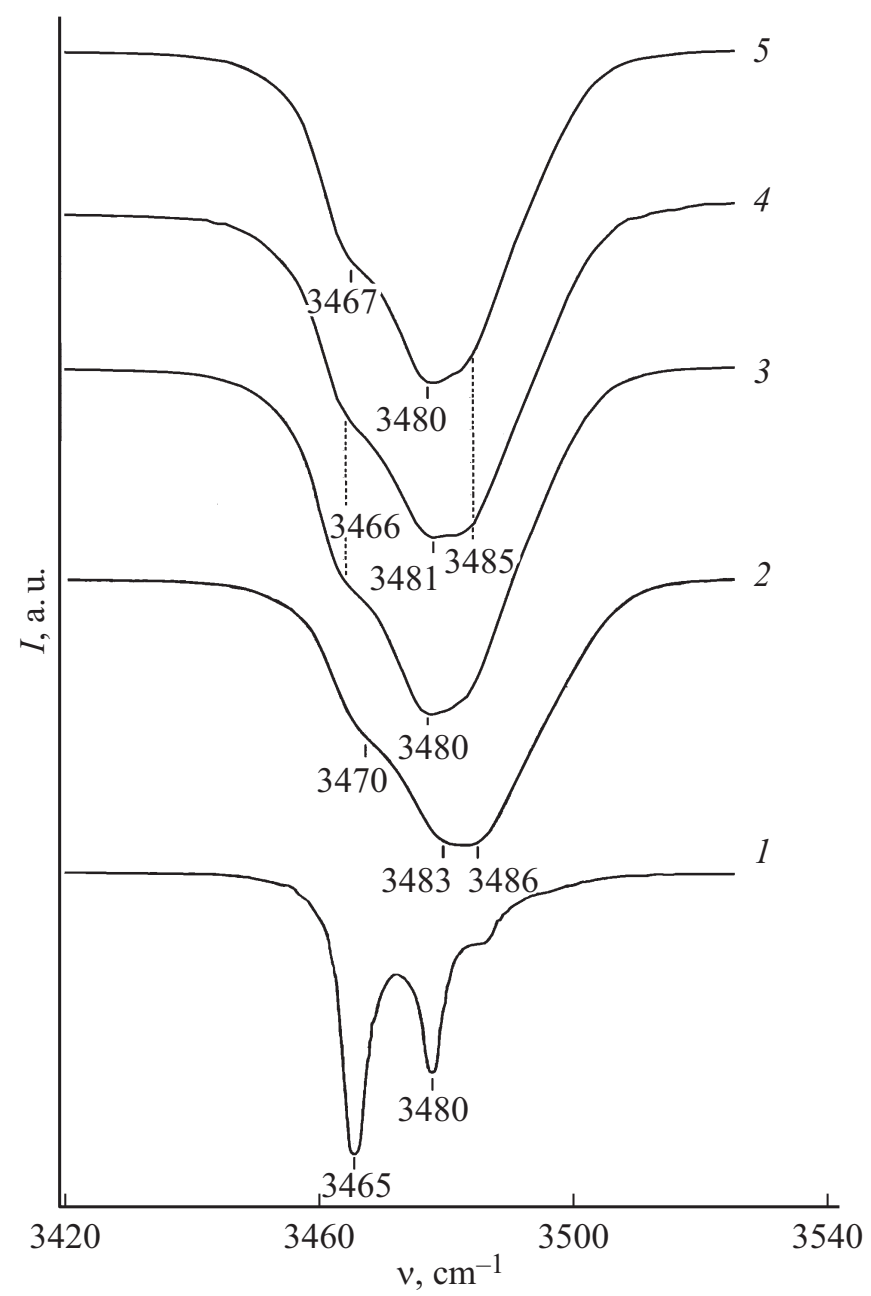

Рис. 4. Спектры ИК-поглощения кристаллов: $1-\mathrm{LiNbO}_{3 \text { stoich, }}$ $2-\mathrm{LiNbO}_{3 \text { cong }}, 3-\mathrm{LiNbO}_{3}: \mathrm{B}\left(0.55 \mathrm{~mol} \% \mathrm{~B}_{2} \mathrm{O}_{3}\right.$ в шихте $)$, $4-\mathrm{LiNbO}_{3}: \mathrm{B}\left(0.69\right.$ mol.\% $\mathrm{B}_{2} \mathrm{O}_{3}$ в шихте $), 5-\mathrm{LiNbO}_{3}: \mathrm{B}$ (0.83 mol.\% $\mathrm{B}_{2} \mathrm{O}_{3}$ в шихте).

сталла (табл. 2). При этом ширины всех компонентов полосы поглощения кристаллов $\mathrm{LiNbO}_{3}$ : В меньше, чем для кристалла $\mathrm{LiNbO}_{3 \text { cong, }}$ за исключением полосы с частотой $3485 \mathrm{~cm}^{-1}$ (табл. 2), что свидетельствует об упорядочении в расположении ОН-групп в структуре

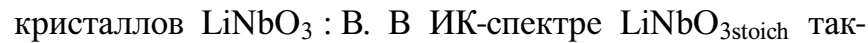
же наблюдается три компонента полосы поглощения с частотами 3465,3480 и $3488 \mathrm{~cm}^{-1}$ (рис. 4) в отличие от данных работы [10], согласно которым в спектре стехиометрического кристалла в области валентных колебаний ОН-групп наблюдается одна полоса поглощения $\left(3465 \mathrm{~cm}^{-1}\right)$. Этот факт свидетельствует о наличии в структуре выращенного нами кристалла $\mathrm{LiNbO}_{3 \text { stoich }}$ комплексных дефектов. Авторы работы [10] предполагают, что $\mathrm{LiNbO}_{3 \text { stoich }}$ можно рассматривать как кристалл, легированный примесью $\mathrm{Nb}^{5+}$, таким образом, в структуре $\mathrm{LiNbO}_{3 \text { stoich }}$ существует дефектный комплекс $\mathrm{Nb}_{\mathrm{Nb}}^{5+}-\mathrm{OH}$. Полоса поглощения с частотой $3465 \mathrm{~cm}^{-1}$ соответствует валентным колебаниям комплексного дефекта $\mathrm{Nb}_{\mathrm{Nb}}^{5+}-\mathrm{OH}$ в кристалле $\mathrm{LiNbO}_{3 \text { stoich. По сравнению }}$ с другими исследованными кристаллами ширины компонентов ИК-спектра кристалла $\mathrm{LiNbO}_{3 \text { stoich }}$ значительно более узкие (рис. 4, табл. 2), что указывает на большую упорядоченность подрешетки протонов в стехиометрическом кристалле по сравнению с конгруэнтным кристаллом и кристаллами $\mathrm{LiNbO}_{3}: \mathrm{B}$.

Концентрация ОН-групп в исследованных кристаллах, рассчитанная из ИК-спектра поглощения по методу Клавира [32], минимальна для кристаллов $\mathrm{LiNbO}_{3 \text { stoich }}$ и максимальна для кристаллов $\mathrm{LiNbO}_{3}$ : В (0.55 и 0.83 mol.\% $\mathrm{B}_{2} \mathrm{O}_{3}$ в шихте) (табл. 2). Кристаллы $\mathrm{LiNbO}_{3 \text { cong }}$ и $\mathrm{LiNbO}_{3}$ : B (0.69 mol.\% $\mathrm{B}_{2} \mathrm{O}_{3}$ в шихте) по концентрации ОН-групп занимают промежуточное значение (табл. 2). Необходимо отметить, что для кристаллов $\mathrm{LiNbO}_{3 \text { cong }}$ и $\mathrm{LiNbO}_{3}$ : В (0.69 mol.\% $\mathrm{B}_{2} \mathrm{O}_{3}$ в шихте) не наблюдалось раскрытия индикатрисы ФИРС [5] в отличие от кристаллов $\mathrm{LiNbO}_{3 \text { stoich }}$ и $\mathrm{LiNbO}_{3}$ : B $\left(0.55\right.$ и 0.83 mol.\% $\mathrm{B}_{2} \mathrm{O}_{3}$ в шихте), в которых индикатриса ФИРС раскрывается, угол фотоиндуцированного рассеяния света составляет 56,14 и $22^{\circ}$ соответственно (табл. 1 ). 


\section{Заключение}

Исследованы рэлеевское фототоиндуцированное рассеяние света, край фундаментального оптического поглощения, ИК-спектры поглощения в области валентных колебаний ОН-групп в номинально чистых стехиометрическом и конгруэнтном кристаллах $\mathrm{LiNbO}_{3}$, а также в номинально чистых кристаллах $\mathrm{LiNbO}_{3}$ : $\mathrm{B}$, выращенных из шихты, легированной неметаллическим элементом бором. По характеристикам ФИРС для всех исследованных кристаллов выполнена количественная оценка напряженностей фотовольтаического и диффузионного полей. Показано, что величина диффузионного поля, отвечающего за диффузионный механизм переноса заряда для кристаллов $\mathrm{LiNbO}_{3}: \mathrm{B}$, имеет промежуточное значение между кристаллами конгруэнтного и стехиометрического состава и зависит от концентрации бора в шихте. При этом кристаллы $\mathrm{LiNbO}_{3}$ : В по сравнению со стехиометрическим кристаллом отличаются меньшим углом раскрытия индикатрисы ФИРС, также зависящим от концентрации бора в шихте. Ширина запрещенной зоны кристаллов $\mathrm{LiNbO}_{3}$ : В соответствует значению для стехиометрического кристалла, но при этом кристаллы $\mathrm{LiNbO}_{3}$ : В отличаются большей оптической однородностью по сравнению со стехиометрическим кристаллом. Показано, что расположение в структуре ОН-групп в кристаллах $\mathrm{LiNbO}_{3}$ : В более упорядочено, чем в конгруэнтном кристалле. Таким образом, применение для выращивания номинально чистых кристаллов ниобата лития расплава, структурированного неметаллическим элементом бором, позволяет регулировать особенности вторичной структуры, оптическую однородность, величины фотоэлектрических полей и ширину запрещенной зоны в кристалле.

\section{Конфликт интересов}

Авторы заявляют, что у них нет конфликта интересов.

\section{Список литературы}

[1] Сидоров Н.В., Палатников М.Н., Яничев А.А., Титов Р.А., Теплякова Н.А. // Опт. и спектр. 2016. T. 121. № 1. C. 40-49. DOI: $10.7868 / \mathrm{S} 0030403416070199$ [Sidorov N.V., Palatnikov M.N., Yanichev A.A., Titov R.A., Teplyakova N.A. // Opt. Spectr. 2016. Vol. 121. N 1. P. 1024-1032. DOI: 10.1134/S0030400X16070195]

[2] Сидоров Н.В., Палатников М.Н., Яничев А.А., Титов Р.А., Теплякова Н.А. // ЖПС. 2016. Т. 83. № 5. С. 707-714. [Sidorov N.V., Palatnikov M.N., Yanichev A.A., Titov R.A., Teplyakova N.A. // J. Appl. Spectr. 2016. Vol. 83. N 5. P. 750-756.

[3] Палатников М.Н., Сидоров Н.В., Титов Р.А., Теплякова Н.А., Макарова О.В. // Персп. матер. 2018. № 6. C. 5-15. DOI: 10.30791/1028-978X-2018-6-5-15
[4] Сидоров Н.В., Теплякова Н.А., Титов Р.А., Палатников М.Н. // Сибирский физический журн. 2018. Т. 13. № 2. C. 70-79. DOI: 10.25205/2541-9447-2018-13-2-70-79

[5] Сидоров Н.В., Теплякова Н.А., Титов Р.А., Палатников М.Н. // ЖТФ. 2018. Т. 88. Вып. 12. С. 1820 1828. DOI: $10.21883 / J T F .2018 .12 .46783 .39-18$ [Sidorov N.V., Teplyakova N.A., Titov R.A., Palatnikov M.N. // Tech. Phys. 2018. Vol. 63. N 12. P. $1758-1766$. DOI: $10.1134 / \mathrm{S} 1063784218120198]$

[6] Макарова О.В., Палатников М.Н., Бирюкова И.В., Теплякова Н.А., Сидоров Н.В. // Неорган. матер. 2018. T. 54. № 1. C. 53-58. DOI: 10.7868/S0002337X18010104 [Makarova O.V., Palatnikov M.N., Biryukova I.V., Teplyakova N.A., Sidorov N.V. // Inorg. Mater. 2018. Vol. 54. N 1. P. 49-54. DOI: $10.1134 /$ S0020168518010089]

[7] Сидоров Н.В., Палатников М.Н., Теплякова Н.А., Сюй A.B. // ЖПС. 2018. Т. 85. № 4. С. 666-672.

[8] Shur V.Ya., Akhmatkhanov A.R., Baturin I.S. // Appl. Phys. Rev. 2015. Vol. 2. P. 040604-0406015. DOI: $10.1063 / 1.4928591$

[9] Sidorov N.V., Serebryakov Yu.A. // Ferroelectrics. 1994. Vol. 160. P. 101-105.

[10] Lengyel K., Peter A., Kovacs L., Corradi G., Palfavi L, Hebling J., Unferdorben M., Dravecz G., Hajdara I., Szaller Zs., Polgar K. // Appl. Phys. Rev. 2015. Vol. 2. P. 040601-040628. doi.org/10.1063/1.4929917

[11] Cabrera J.M., Olivares J., Carrascosa M., Rams J., Müller R., Diéguez E. // Adv. Phys. 1996. Vol. 45. N 5. P. 349-392. DOI: $10.1080 / 00018739600101517$

[12] Goulkov M., Imlau M., Woike Th. // Phys. Rev. B. 2008. Vol. 77. P. 235110-1-23510-7. DOI: 10.1103/PhysRevB.77.235110

[13] Палатников М.Н., Сидоров Н.В., Бирюкова И.В., Щербина О.Б., Калинников В.Т. // Персп. матер. 2011. № 2. C. $93-97$.

[14] Палатников М.Н., Сидоров Н.В., Макарова О.В., Бирюкова И.В. Фундаментальные аспекты технологии сильно легированных кристаллов ниобата лития. Апатиты: Издво КНЦ РАН, 2017. $241 \mathrm{c}$.

[15] Syuy A.V., Sidorov N.V., Gaponov A.Y., Palatnikov M.N., Efremenko V.G. // Optik. 2013. Vol. 124. N 21. P. 5259-5261. DOI: 10.1016/j.jileo.2013.03.082

[16] Сюй А.В., Сидоров Н.В., Палатников М.Н., Штарев Д.С., Антонычева Е.А., Гапонов А.Ю., Чехонин К.А. // Оптич. журн. 2015. Т. 82. № 5. С. 71-75.

[17] Гурзадян Г.Г., Дмитриев В.Г., Никогосян Д.Н. Нелинейнооптические кристаллы. Свойства и применение в квантовой электронике. М.: Радио и связь, 1991. 160 с.

[18] Сидоров Н.В., Волк Т.Р., Маврин Б.Н., Калинников В.Т. Ниобат лития: дефекты, фоторефракция, колебательный спектр, поляритоны. М.: Наука, 2003. 255 с.

[19] Автореф. канд. дис. Саллум М.И. Влияние стехиометрии и допирующих примесей на электрические и оптические свойства кристаллов ниобата лития. СПб, 2009. 19 с.

[20] Nahm H.H., Park C.H. // Phys. Rev. B. 2008. Vol. 78. N 18. P. $184108 / 1$. DOI: https://doi.org/10.1103/PhysRevB.78.184108

[21] Iyi N., Kitamura K., Izumi F., Yamamoto J.K., Hayashi T., Asano H., Kimura S. // J. Solid State Chem. 1992. Vol. 101. P. 340-352. DOI: 10.1016/0022-4596(92)90189-3.

[22] Blümel J., Born E., Metzger T. // J. Phys. Chem. Solid. 1994. Vol. 55. P. 589-593. DOI: 10.1016/0022-3697(94)90057-4 
[23] Volk T., Wöhlecke M. Lithium niobate. Defects, photorefraction and ferroelectric switching. Berlin: Springer, 2008. $250 \mathrm{p}$.

[24] Блистанов А.А., Любченко В.М., Горюнова А.Н. // Кристаллография. 1998. Т. 43. № 1. С. 86-91.

[25] Лайнс М., Гласс А. Сегнетоэлектрики и родственные им материалы. М.: Мир, 1981. 736 с.

[26] Автореф. канд. дис. Обуховский В.В. Процессы фоторефрактивного рассеяния света в кристаллах. Киев, 1989. 24 с.

[27] Ахмадуллин И.Ш., Голенищев-Кутузов В.А., Мигачев С.А., Миронов С.П. // ФТТ. 1998. Т. 40. Вып. 7. С. 1307-1309. [Akhmadullin I.Sh., GolenishchevKutuzov V.A., Migachev S.A., Mironov S.P. // Phys. Sol. State. 1998. T. 40. N 7. C. 1190-1192. DOI: $10.1134 / 1.1130517]$

[28] Fontana M.D., Bourson P. // Appl. Phys. Rev. 2015. N 2. P. 040602-1-040602-14. https://doi.org/10.1063/1.4934203

[29] Polgar K., Peter A., Kovacs L., Corradi G., Szaller Zs. // J. Cryst. Growth. 1997. Vol. 177. N 3.4. P. 211-216. https://doi.org/10.1016/S0022-0248(96)01098-6

[30] Kong Y., Zhang W., Chen X., Xu J., Zhang G. // J. Phys. Cond. Matter. 1999. Vol. 11. P. 2139-2143.

[31] Kong Y., Zhang W., Xu J., Yan W., Liu H., Xie X., Li X., Shi L., Zhang G. // Infrared Phys. Techn. 2004. Vol. 45. P. 281-289. DOI: 10.1016/j.infrared.2003.12.001

[32] Klauer S., Wöhlecke M., Kapphan S. // Phys. Rev. B. 1992. Vol. 45. P. 2786-2799.

https://doi.org/10.1103/PhysRevB.45.2786 